\title{
TU/e emonownen

\section{Automated two-way coupling of CFD fire simulations to thermomechanical FE analyses at the overall structural level}

\section{Citation for published version (APA):}

Feenstra, J. A., Hofmeyer, H., van Herpen, R. A. P., \& Mahendran, M. (2018). Automated two-way coupling of CFD fire simulations to thermomechanical FE analyses at the overall structural level. Fire Safety Journal, 96, 165-175. https://doi.org/10.1016/j.firesaf.2017.11.007

DOI:

10.1016/j.firesaf.2017.11.007

Document status and date:

Published: 01/03/2018

\section{Document Version:}

Accepted manuscript including changes made at the peer-review stage

\section{Please check the document version of this publication:}

- A submitted manuscript is the version of the article upon submission and before peer-review. There can be important differences between the submitted version and the official published version of record. People interested in the research are advised to contact the author for the final version of the publication, or visit the $\mathrm{DOI}$ to the publisher's website.

- The final author version and the galley proof are versions of the publication after peer review.

- The final published version features the final layout of the paper including the volume, issue and page numbers.

Link to publication

\section{General rights}

Copyright and moral rights for the publications made accessible in the public portal are retained by the authors and/or other copyright owners and it is a condition of accessing publications that users recognise and abide by the legal requirements associated with these rights.

- Users may download and print one copy of any publication from the public portal for the purpose of private study or research.

- You may not further distribute the material or use it for any profit-making activity or commercial gain

- You may freely distribute the URL identifying the publication in the public portal.

If the publication is distributed under the terms of Article 25fa of the Dutch Copyright Act, indicated by the "Taverne" license above, please follow below link for the End User Agreement:

www.tue.nl/taverne

Take down policy

If you believe that this document breaches copyright please contact us at:

openaccess@tue.nl

providing details and we will investigate your claim. 
Automated coupling of CFD fire simulations to thermomechanical FE analyses at the structural level

Feenstra, J.A.; Hofmeyer, H.; Van Herpen, R.A.P.; Mahendran, M.

\title{
Keywords
}

Fire safety, thermomechanical analyses, CFD-FEM coupling, two-way coupling, adiabatic surface temperature

\begin{abstract}
Coupled CFD fire simulations and thermomechanical FE analyses typically consist of fire simulations, heat transfer analyses and structural response analyses, mutually coupled by three coupling steps. There are two coupling approaches, one-way and two-way coupling, where two-way coupling includes the effects of structural response on fire propagation. In the first part of this paper, one- and two-way coupling approaches including the coupling steps are proposed to include coupling at the structural level. Then a case study comprising an office space with a 12-plate thin-walled steel façade under fire conditions is introduced, as well as the related CFD and FE models. A newly developed automated coupling interface and subprograms are used to perform several one-way and two-way coupled analyses using a coarse and fine CFD mesh for the case study. Slight differences are found in the results of identical simulations due to random effects in the fire simulations. Nevertheless, it can be concluded that two-way coupling is feasible, and that significant differences in the façade failure progression illustrate its effectiveness. Future research includes additional developments of both the fire and structural models, as well as verification and parametric studies to further confirm the findings.
\end{abstract}

\section{Introduction}

With an ever-evolving built environment, new challenges arise for fire fighters and researchers. For example, the growing complexity of architectural designs, structural optimization, and the use of innovative building materials and construction techniques introduce new types of fire risks. Therefore an improved understanding of fires, and methods for predicting temperature and smoke development are critical to both structural integrity and human safety.

The common approach used to assess the effects of a fire in structural engineering is to subject a loaded structural element with prescriptive time-temperature curves and to evaluate its behaviour. The fire safety check involves the structural element meeting a criterion that specifies a certain time for which the element should resist the fire [1]. This approach based on prescriptive time-temperature curves cannot accurately model the real fire conditions and does not take into account the 3D dependency of both the fire compartment and the structural system.

Advancements in the analyses of structures under fire involve the utilization of advanced numerical methods to both simulate the fire and to analyse the structure's thermal and structural behaviour [2]. More specifically they use Computational Fluid Dynamics (CFD) simulation to model the fire driven fluid flow and subsequently to couple this to thermal and structural Finite Element (FE) analyses of the structural system under consideration. The combination of CFD simulations and FE analyses is commonly referred to as coupled fire and thermomechanical analysis or coupled CFD-FEM (Finite Element Method). The interest in the structural response to fire and coupled approaches have been further developed by the collapse of the World Trade Centre (WTC) towers in 2001. This led to the American National Construction Safety Team's (NCST) recommendations to enable software to study realistic fire behaviour, to analyse building response to fire, and to assist in the design of new fire protection systems [3] However, the development of coupled CFD-FEM approach is not a trivial task since challenges are found in the underlying differences between the CFD and FE models in relation to for example, the discretization, algorithms and time scales. For example, Yu and Jeffers showed successfully that averaging time in the transfer of CFD data to an FE model improves FE convergence and thus computational costs [4], while Beata and Jeffers developed a trapezoid rule algorithm to 
overcome differences in the mesh size or node locations between CFD and FE models. Compared to other algorithms based on averaging, sampling, and least squares, their method was shown to be increasingly more accurate and efficient [5].

Prasad and Baum [6] have developed an interface model, called Fire Structural Interface (FSI), which can be used to generate realistic thermal boundary conditions for the heating of complex structures. Their interface model, used in the analysis of the collapse of the WTC towers, couples a fire simulation using Fire Dynamics Simulator (FDS) [7] to a structural analysis using ANSYS, based on heat transfer by radiation and conduction. Later research by Baum [8] discusses the potential to predict the effect of fire on building structures by coupled fire to thermo-mechanical analyses. More specifically, it discusses the role of uncertainty in input parameters and the challenges found in the differences in spatial and temporal length scales, numerical techniques, the complexity of the computer codes, and the required computational resources for coupled CFD-FEM analyses. Also Baum [8] underlines the importance of the development of coupled CFD-FEM models for the quantitative assessment of fire effects on structures. A coupled CFD-FEM analysis can be split into three separate parts: (a) fire simulation; (b) heat transfer analysis; and (c) structural response analysis. They are mutually coupled by coupling steps. Two main approaches to coupling exist. For a one-way coupled approach, data is transferred from CFD simulation to FE analysis and, for two-way coupling additionally the data from FE analysis is returned to CFD simulation. The European research project FIRESTRUC, presented by Welch et al. [9] analysed both coupling approaches in predicting a structure's thermo-mechanical behaviour. It presents a broad examination of approaches to coupling CFD and FEM codes first. Then the three parts, fire simulation, heat transfer analysis, and structural response analysis are introduced as well as their mutual coupling steps. Multiple implementation methods are proposed and discussed for both one- and two-way coupling approaches, and the variables that should be transferred between CFD simulations and FE analyses are also identified. Luo et al. [10] [11] have developed a Fire Interface Simulator Toolkit (AFIST) by integrating FDS with a customized Abaqus structural analyser. A two-way coupling between the fire simulation and heat transfer models was integrated, where heat and mass flow are exchanged at the incremental level. A time-to-failure prediction of a sandwich panel was used for validation and the toolkit was applied to demonstrate the response of a loaded composite panel to a pool fire.

In chronological order, the so-called Adiabatic Surface Temperature (AST) was introduced as a concept by Wickström et al. in 2007 [12]. It is a tool to express the thermal exposure of a surface to fire in a single quantity, thereby reducing the data flow in a coupled analysis. Duthinh et al. [2] utilized the AST to develop their interface between fire simulation software FDS and FEM software ANSYS, and simulated a trussed beam and verified it using a real fire test by NIST. In 2009, Banerjee et al. [13] created an Immersive Visualization Environment (IVE) to visualize and study in real time the structural and thermal behaviour of a chosen structural element in a one-way coupled fire to thermo-mechanical analysis (using FDS and Abaqus). Recently, Silva et al. [14] developed a computational Fire-ThermoMechanical Interface (FTMI) to provide an interface for firethermomechanical performance based analysis of structures under fire. The interface allows for oneway coupling of an FDS fire simulation to a thermomechanical ANSYS analysis, taking into account both convective and radiative heat transfer to the exposed surface via the AST concept. In their paper the methodology is described and applied to evaluate the fire-thermomechanical behaviour of an $\mathrm{H}$ section as column under a localized fire. In addition, the implemented code has been added to the FDS repository under the name FDS2FTMI (using among others FDS2ASCII) to allow for one-way coupling of FDS and the finite element program ANSYS. Most recently, additional validation of FDS2FTMI was completed by Zhang et al. [15].

The overview above presents the various approaches and challenges in the coupling of fire simulations to thermomechanical analyses. Coupling methodologies in literature focus on fire-to-thermal and thermal-to-structural coupling steps, both one-way and two-way. However, the effects of changes at the structural level during fire propagation and further structural failure progression is missing so far. For instance, failures of a window or a local structural element result in openings that change the fire behaviour, and consequently influence the fire load on the structural elements. 
The contribution of this paper is to introduce this problem and to investigate the feasibility of an automated one-way and two-way coupling of CFD fire simulations to thermomechanical FE analyses at the structural level. Additionally it assesses the effectiveness of two-way coupling by illustrating the difference in failure progression of a thin-walled steel façade in a two-way coupled analysis compared to a sequential one-way coupled analysis. The approach is discussed in Section 2; a case study is presented in Section 3; the program and scripts are introduced in Section 4, which is followed by results in Section 5 and several verification steps in Section 6. Finally, Section 7 gives a discussion, followed by conclusions in Section 7 .

\section{Approach}

As shown in Figure 1, a coupled fire to thermomechanical analysis consists of three parts: (A1) a fire simulation; (A2) a heat transfer analysis; and (A3) a structural response analysis. Moreover, these parts are mutually coupled by three steps: (C1) coupling of fire simulation to heat transfer analysis, (C2) coupling of heat transfer analysis to structural response analysis; and (C3) coupling of structural response analysis to fire simulation. Now a distinction can be made between one-way and two-way coupling procedures where for two-way coupling the influence of structural changes on the fire propagation is taken into account by coupling (C3), whereas (C3) is not used for one-way coupling. These two approaches differ in their implementation, as one-way coupling is a linear process while two-way coupling needs to be solved iteratively: The one-way coupled analysis consists of a fire simulation for the full duration of the intended analysis and then continues sequentially with the heat transfer and structural response analyses, again for the full duration. Instead, in the two-way coupled analysis it is needed to verify, during the fire simulation, if some parts of the structural model have changed and, if positive, to undertake appropriate modification in the fire and FE models. Therefore time increments are used in the coupled analysis: the fire needs to be simulated for a time increment, and then if the thermomechanical analysis reveals significant geometric changes, they are updated for the subsequent time increment of the fire simulation. Ideally, the size of the time increments for the coupled analysis would be the minimum of the required time increment for the fire simulation (i.e. for simulation quality and capturing relevant phenomena) and the required time increment for the thermomechanical analysis (e.g. a failed panel should be detected on time). As such it can be seen that two-way coupling is a combination of a number of one-way coupled fire to thermomechanical simulations, where following each one-way-coupled increment, the geometry is updated in the fire, thermal, and structural models. To be able to introduce coupling step (C1) first, the adiabatic surface temperature is explained in Section 2.1.

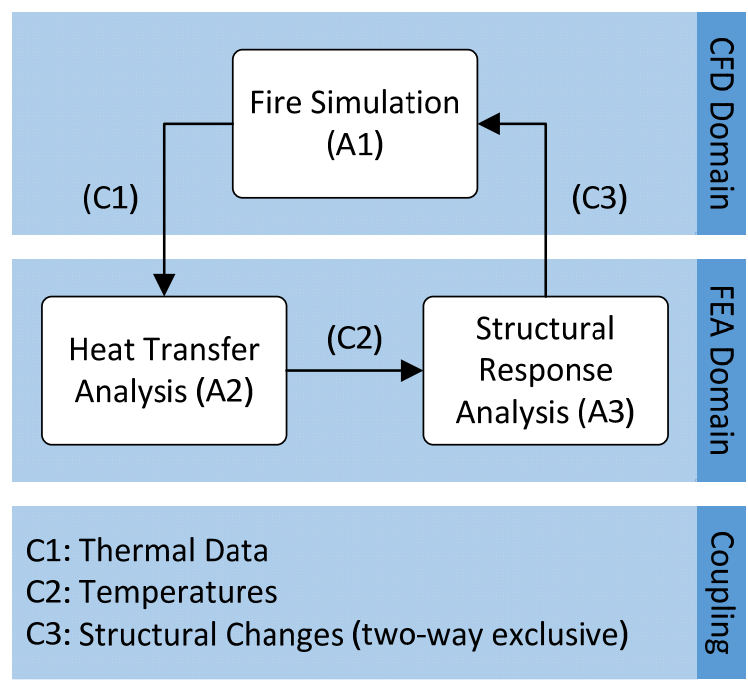

Figure 1. Approach for one-way and two-way coupled fire to thermomechanical analyses. (Three analysis parts and three coupling steps can be identified) 


\subsection{Adiabatic Surface Temperature}

During a fire, energy is transferred from flames to exposed structural surfaces via the modes of convective and radiative heat transfer. The total net heat flux $q_{t o t, S M}^{\prime \prime}\left[\mathrm{W} / \mathrm{m}^{2}\right]$ to an exposed structure can be expressed as the sum of these two heat transfer modes:

$$
q_{\text {tot }, S M}^{\prime \prime}=\varepsilon\left(q_{i n c, F M}^{\prime \prime}-\sigma T_{\text {surf }, S M}{ }^{4}\right)+h_{c}\left(T_{\text {gas }, F M}-T_{\text {surf }, S M}\right)
$$

where $\varepsilon$ is the emissivity, $q_{i n c, F M}^{\prime \prime}\left[\mathrm{W} / \mathrm{m}^{2}\right]$ is the incident radiation heat flux, $\sigma\left[\mathrm{W} /\left(\mathrm{m}^{2} \mathrm{~K}^{4}\right)\right]$ is the Stefan Boltzmann constant, $T_{\text {surf,SM }}[\mathrm{K}]$ is the surface temperature, $h_{c}\left[\mathrm{~W} /\left(\mathrm{m}^{2} \mathrm{~K}^{1}\right)\right]$ is the heat transfer coefficient, and $T_{\text {gas,FM }}[\mathrm{K}]$ is the gas temperature. The subscripts $F M$ and $S R$ denote the fire and structural model respectively. Equation (1) above presents a dependency of the net heat flux on both the fire and structural model and therefore an iterative approach is needed: Incident radiative heat fluxes and convective properties should be transferred from the fire simulation to the heat transfer analysis and vice versa to accurately predict the thermal loading. However, this is a challenging task considering the difference in discretization and time scales between both simulation types. Therefore the concept of the Adiabatic Surface Temperature (AST) was developed by Wickström et al. [10]. The AST is the temperature of an imaginary perfect insulator exposed to the same heating (fire) conditions as the real surface and can be used in transferring data from fire to thermal or structural models. The net total heat flux to this ideal surface is by definition zero, thus:

$$
q_{\mathrm{tot}, S M}^{\prime \prime}=\varepsilon\left(q_{i n c, F M}^{\prime \prime}-\sigma T_{A S T}{ }^{4}\right)+h_{c}\left(T_{g a s, F M}-T_{A S T}\right)=0
$$

where $T_{A S T}[\mathrm{~K}]$ is the adiabatic surface temperature (AST), to be calculated by Equation (2) and is often selectable as output from CFD software. In the heat transfer or structural response analyses, the total net heat flux $q_{\text {tot }}^{\prime \prime}$ to an exposed structural surface, using AST, can then be computed as:

$$
q_{t o t, S M}^{\prime \prime}=\varepsilon \sigma\left(T_{A S T}{ }^{4}-T_{\text {surf }, S M}{ }^{4}\right)+h_{c}\left(T_{A S T}-T_{\text {surf }, S M}\right)
$$

Thus the AST reduces the data flow to the structural model by eliminating the dependency of the surface temperature on the net heat flux, thereby limiting the amount of variables to transfer to a single scalar quantity and removing the dependency of the net heat flux to both fire and structural models.

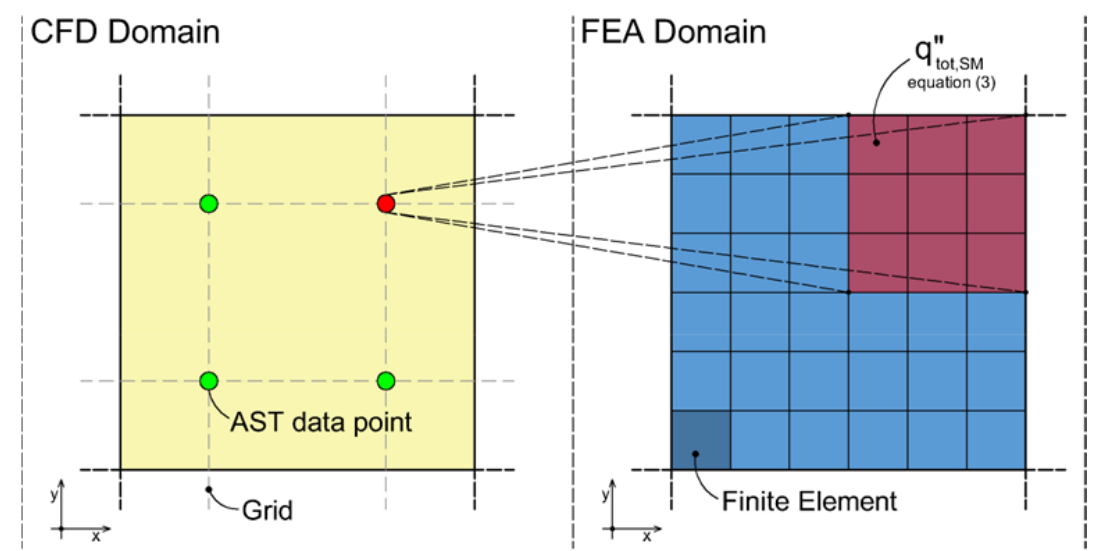

Figure 2. Assigning the recorded AST at predefined data points in CFD fire simulation to each integration point in $F E$ heat transfer analyses

2.2 Coupling fire simulation to heat transfer analysis (C1)

For most CFD fire simulation programs, at a flow obstruction - here being the structural system with adiabatic properties, it is possible to define a grid with points for which AST data can be recorded. 
Consequently, this AST data can be used for boundary conditions to map the combined convective and radiative thermal heat flux, as expressed in Equation (3), to the exposed structural surface of the finite element heat transfer analysis. Logically, for each integration point on the surface of the FE model, the values of the nearest data point of the CFD model should be used (Figure 2). Based on the boundary conditions, time varying nodal temperature data can then be simulated and recorded in the finite element heat transfer analysis. A similar approach has been used by Silva et al. [14].

\subsection{Coupling heat transfer analysis to structural response analysis (C2)}

For the structural response analysis, the displacements and their derived strains and stresses are governed by thermal effects. Namely, restricting thermal expansion results in stresses, the so-called thermal stresses. For a 1D system these stresses can be expressed as:

$$
\sigma_{t h}=-\alpha \cdot \Delta T \cdot E
$$

where $\sigma_{t h}\left[\mathrm{~N} / \mathrm{m}^{2}\right]$ is the thermal stress, $\alpha\left[{ }^{\circ} \mathrm{C}^{-1}\right]$ is the coefficient of thermal expansion, $\Delta T\left[{ }^{\circ} \mathrm{C}\right]$ is the temperature difference, and $E\left[\mathrm{~N} / \mathrm{m}^{2}\right]$ is Young's modulus. For steel $\alpha=12 \cdot 10^{-6}{ }^{\circ} \mathrm{C}^{-1}$ and $E=210 \cdot 10^{9} \mathrm{~N} / \mathrm{m}^{2}$. Therefore when for steel thermal expansion is not possible, stresses develop at a rate of $2.52 \mathrm{~N} /\left(\mathrm{mm}^{2}{ }^{\circ} \mathrm{C}\right)$. To relax these thermal stresses a structure may buckle (bend), and then effectively exchanges compressive thermal stresses to structural bending stresses.

The time varying nodal temperature data from the heat transfer analysis can be applied as boundary conditions in the structural response model. The mechanical response and structural changes (displacements, strains and stresses) can then be recorded for all (exterior) integration points. Considering the assumed time and structural scale, both heat generation due to deformations and the disturbance of the conductance flow field due to occurrence of gaps are negligible. This essentially means one-way coupling can be performed between heat transfer and structural response analyses.

\subsection{Coupling structural response analysis to fire simulation (C3)}

The last coupling step, exclusively to two-way coupling, consists of two parts. First (partial) failure of the structural system is analysed based on a failure criterion and secondly the CFD model of fire simulation and the FE models of heat transfer and structural response analyses are updated accordingly. For the failure criterion, a simplified stress based approach is suggested that checks if the von Mises stress has exceeded the yield stress at all integration points at the outer surface for each finite element. If a user defined threshold is exceeded the finite element can be considered failed. In turn (a part of) a structural system can be considered as failed when a user-defined number of failed finite elements is present, and consequently this part is removed (Figure 3). For updating of the CFD and FE models, the relatively small deformations due to thermal expansion are believed to have a negligible effect on fire propagation, certainly when compared with the removal of structural parts, and thus are not included in the feedback loop. Besides, these small deformations would be difficult to implement due to the difference in discretization type and scale between the CFD and FE models.

\section{Case Study}

In the previous section coupling steps were discussed. In this section, a model room is introduced and the fire simulation, heat transfer analysis and structural response analysis are discussed. The discussion involves CFD software Fire Dynamics Simulator (FDS) and FE analysis software Abaqus, however, a similar approach should be possible with other CFD and FE analysis software.

\subsection{Model room}

In order to demonstrate and assess the effectiveness of two-way coupling, a model room was selected as shown in Figure 4. This model comprises a standard office with $3.6 \mathrm{~m}$ width, $5.4 \mathrm{~m}$ length and 2.7 $\mathrm{m}$ height. The office space is modelled as a stand-alone room; neighbouring rooms and the corridor are not modelled. Yu . This door acts as a passive opening to allow sufficient amount of oxygen to be drawn from the corridor into the office space. The separation walls and floors are thought to be 
constructed of concrete with the exception of the façade, which comprises a thin-walled steel façade system of $4 \times 3$ sandwich panels on a steel frame. The sandwich panels are simplified to steel plates of $A_{\text {panel }}=0.81 \mathrm{~m}^{2}$ and thickness $t_{\text {panel }}=3 \mathrm{~mm}$, each simply supported along their horizontal edges. Failure of the panels is modelled as a direct connection to the outside allowing additional air to flow into the compartment, and consequently this influences the fire.
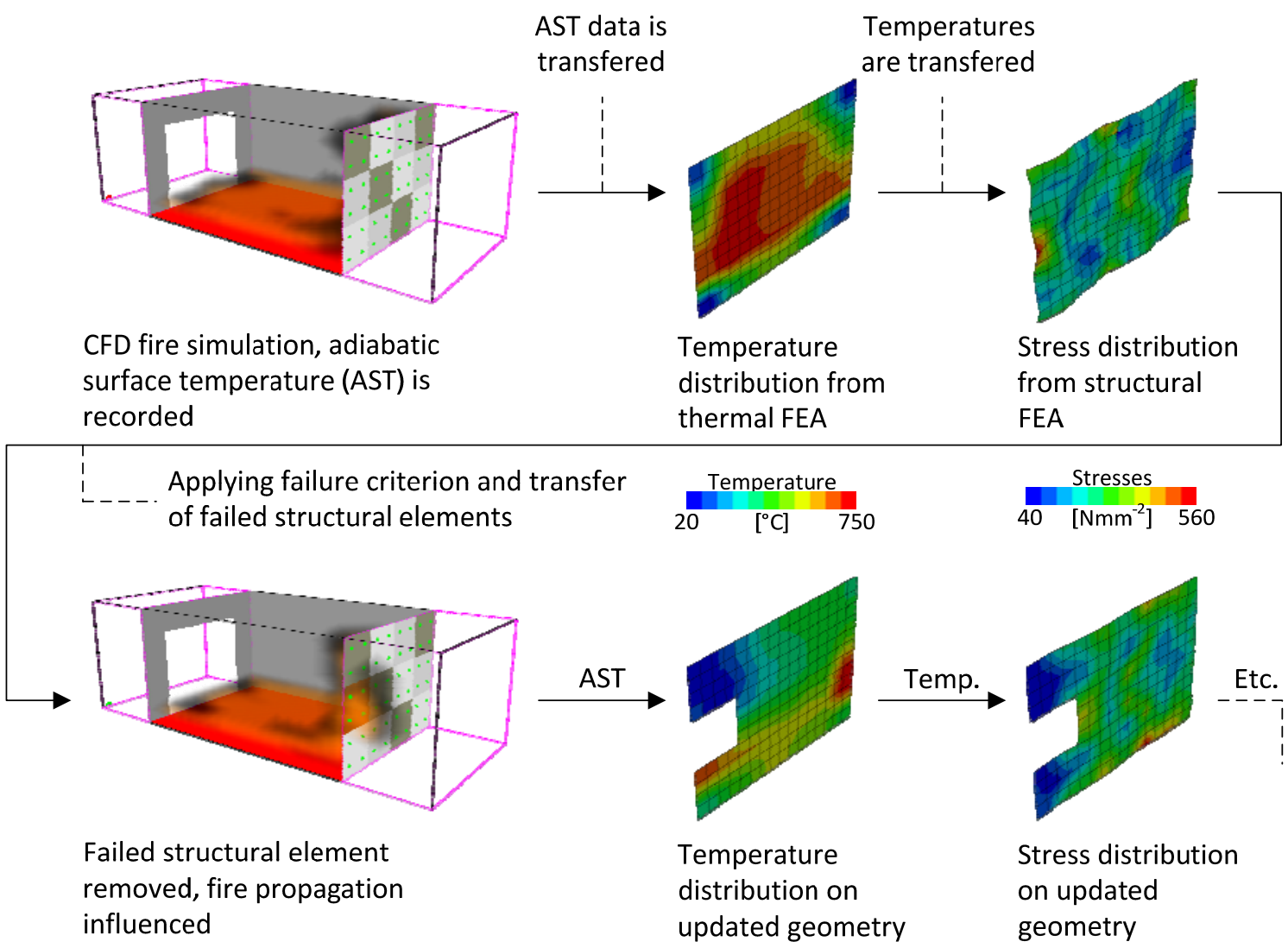

Figure 3. Two-way coupled fire to thermomechanical analysis using a stress-based failure criterion

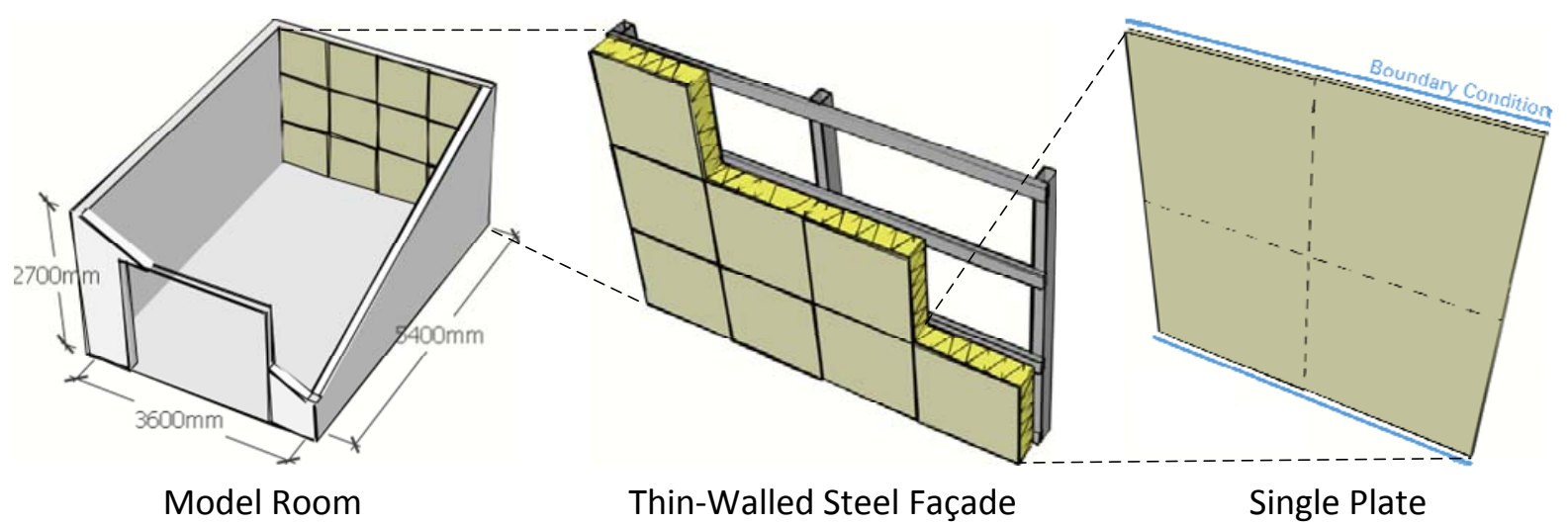

Figure 4. Model room with a thin-walled steel façade made of single plates

\subsection{Fire simulation (A1)}

The Computational Fluid Dynamics (CFD) code Fire Dynamics Simulator (FDS) [7] is used to simulate a fire in the above model room. The office is modelled and meshed using both a coarse and fine mesh of cuboid cells with rib sizes of $0.30 \mathrm{~m}$ and $0.15 \mathrm{~m}$, respectively. The computational domain is extended $1.8 \mathrm{~m}$ on both sides in the length direction to allow air to be drawn into the compartment. A fully developed fire is assumed and applied uniformly over the floor area of 3.6 * $5.4 \mathrm{~m}^{2}$. The fire is ramped linearly over $10 \mathrm{~s}$ to a heat release rate (HRR) of $250 \mathrm{~kW} / \mathrm{m}^{2}$ and is kept 
constant for the remainder of the simulation, effectively limiting the fire simulation to the flashover and fully developed phase. The HRR is limited to $250 \mathrm{~kW} \cdot \mathrm{m}^{-2}$ as prescribed by the Eurocode $1-2$ standard for the office occupancy class [1]. Cellulose, with formation enthalpy $-5.13 \mathrm{~kJ} / \mathrm{mol}$, is selected as fuel for the compartment fire, based on the Standard ISO Cellulosic curve (ISO-834). The concrete separation walls and floors are modelled as obstructions with a thickness of $0.3 \mathrm{~m}$, using a density of $1800 \mathrm{~kg} / \mathrm{m}^{3}$, conductivity $1.15 \mathrm{~W} /(\mathrm{mK})$, specific heat $1.00 \mathrm{~kJ} /(\mathrm{kgK})$, and emissivity 0.8 . The façade consists of an array of $4 \times 3$ obstructions with adiabatic properties, with on the surface of each panel four equally spread devices to record the adiabatic surface temperature, measured at $5 \mathrm{~s}$ interval. If in the two-way coupled analysis, failure of a plate has occurred in a previous iteration, then this plate has to be removed from the simulation. This is accomplished by defining a unique device that controls removal for each obstruction. Specifically for FDS, panel removal is accomplished using the restart function of FDS. In the initial setup of the FDS model a unique timed removal is defined for all plate-obstructions with the removal time outside the simulation duration. The actual plate removal time can then be updated to match the failure time before restarting the simulation, effectively removing the obstruction at the beginning of the next iteration. It is important to note that this implies that the size of iteration time step in a two-way coupling is a measure for the delay between failure and removal.

\subsection{Heat transfer analysis (A2)}

For the heat transfer analysis, the 12-plate thin-walled steel façade is modelled with each plate meshed by 36 heat transfer shell finite elements, Abaqus DS8. DS8 is a quadrilateral element with 8 nodes and 9 integration points, each integration point having 5 section points over the thickness of the element. Although it is possible to model thermally and structurally coupled plates by applying the so-called tyings, the plates are assumed as structurally and thermally independent (untied) for the FE heat transfer and structural response analyses (Section 6). Every plate is divided into four temperature partitions representing the surface area related to the device recording the adiabatic surface temperature data in the fire simulation (Figure 2). The steel grade is S355, having a Young's Modulus equal to $2.1 E 11 \mathrm{~N} / \mathrm{m}^{2}$, Poisson's ratio 0.29 , density $7850 \mathrm{~kg} / \mathrm{m}^{3}$, specific heat $452 \mathrm{~J} /(\mathrm{kgK})$, conductivity $53.3 \mathrm{~W} /(\mathrm{mK})$, expansion coefficient $12 E-6 / K$, and a surface film condition of $25 \mathrm{~W} /\left(\mathrm{m}^{2} \mathrm{~K}\right)$, all assumed to be temperature independent. To obtain a solution, an implicit transient heat transfer step is used with a maximum allowed temperature change equal to 50. The AST data from the fire simulation is used as boundary conditions to describe the thermal flux to the partitions of the structural system as expressed in Equation (3) and illustrated in Figure 2. Specifically, in Abaqus, the surface film condition and radiation to the environment interactions can be utilized for this. After the solution, nodal temperature data is obtained at all integration points for each finite element. Finally, the removal of failed plates takes place by using a restart simulation in combination with a model change interaction. For every iteration in the two-way coupling procedure, a restart step is defined after the initial iteration, and the structural model is updated according to its failure history.

\subsection{Structural response analysis (A3)}

The time varying nodal temperature data from the heat transfer analysis is applied as boundary conditions in the structural response model. Here, no additional pre-processing is required since both analyses are performed within the same finite element program Abaqus, which uses data interpolation that even allows for the use of dissimilar meshes between the heat transfer and structural response analyses. Note that as such the structure is temperature loaded; self-weight or other force-based loads are not taken into account. The plates are meshed with 36 quadratic shell finite elements of type Abaqus S8R, having 8 nodes and 4 integration points, with each integration point having 5 section points over the thickness of the element. A dynamic implicit solution procedure is used, including geometric non-linear and elasto-plastic material behaviour, the latter for steel defined by a yield strength equal to $3.2 \cdot 10^{8} \mathrm{~N} / \mathrm{m}^{2}$, followed by hardening with stress-strain points: $3.570 E 8$ for 0.002 , $3.661 E 8$ for 0.0157 , and 5.416E8 for 0.1351 (S355). Displacement and its derivatives, stress and strain, are monitored for all exterior integration points. Stress output is then used to predict plate failure and subsequently these structural changes are applied in the next iteration. For the structural response analysis, plate removal is accomplished by using a model change interaction combined with a restart analysis, similar to the heat transfer analysis above. As the structural system involves thin- 
walled plates, to accurately predict the structural response, an imperfection is implemented based on the first eigen-mode and with a maximum out-of-plane displacement equal to the plate thickness. The required buckling analysis consists of a similar structural model, but now with tied plates and using linear perturbation with a uniform normalized temperature field as unit load.

For this case study coupled temperature-displacement finite elements (like Abaqus specific S4T, S4RT, and S8T) could have been used. However, in future research more advanced structural models will be used (e.g. sandwich panels with an insulation core between skin-layers, fixed with fasteners to cold-formed steel sections etc) that partly need dedicated displacement (only)-elements. This will not cause any problems provided the framework presented here is based on fire simulations, thermodynamical simulations (with temperature finite elements) and mechanical simulations (with displacement finite elements).

\section{Programs and Scripts}

In the previous sections, the approach to coupling, and the fire simulation, heat transfer analysis and structural response analysis were discussed. For automation purposes, the coupling interface FDS-2Abaqus was developed (Figure 5). The central program FDS-2-Abaqus manages the complete coupling procedure. In its current state, it is limited to analysing structures consisting of multiple plates and using a stress-based failure criterion. Initially, the program requests user input that involves the number of plates, temperature partitions, simulation duration, iteration size, and failure criteria parameters. Following this input, the program automatically iterates through various simulations, analyses and coupling steps based on the user-defined simulation duration and iteration size. This allows both the failure progression and the fire propagation to be obtained for the full duration of the (two-way) coupled analysis without additional user input. The programs for the coupling steps (blue in Figure 5) will be explained further in the remainder of this section. The fire simulation, and heat transfer and structural response analyses (orange in Figure 5) have been discussed in the previous sections.

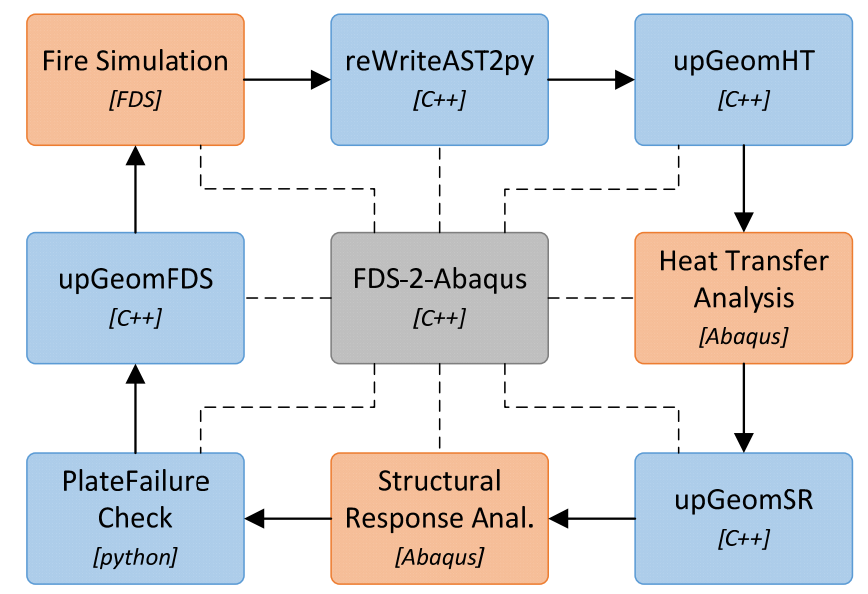

Figure 5. Implementation of fully automated two-way coupled fire to thermomechanical analysis (analysis steps highlighted in orange and coupling steps given in blue)

The program 'upGeomFDS' creates a FDS input file for the current iteration based on an initially supplied basic input file. The latter file is manually written and contains the geometry, discretization, fire definition, and AST output devices. The program copies the basic input file and appends code defining the next iteration and obstruction (plate) removals. The updated input file is then supplied to the FDS program and the fire simulation for the next iteration is performed.

The AST data obtained from FDS is stored in an output file with comma separated values (csv). This csv-file is time ordered, having a separate column for each device that lists the adiabatic surface temperature associated with the time value listed in the first column. After the fire simulation the program 'reWriteAST2Py' inserts the data of the FDS csv-file into a Python script that for each specific device location contains a single list of all time-temperature data. 
The next program 'upGeomHT' updates the Abaqus Heat Transfer (HT) analysis Python script for the current iteration. The program copies a basic heat transfer model and appends additional code based on the current iteration and its failure history, presented below. The basic heat transfer model has been written manually before the simulation and prescribes the structural system comprising the steel plates subdivided into partitions. To this basic model a line is appended to execute the previously generated script containing the time-temperature data of all device locations. Each partition represents the surface area in Abaqus nearest to a FDS device location, and for each partition, code is appended defining the Abaqus surface film conditions and radiation to environment interactions. In addition, code is added to request restart data and defining the time step for the current iteration. Lastly, if plate failure occurred in a previous iteration, code is appended to deactivate the plate via a so-called Abaqus model change interaction.

Similar to the previous program, the program 'upGeomSR' appends additional code to a basic model of the Structural Response (SR) analysis. The basic model contains the structural system comprising the steel plates and includes the simply supported boundary conditions along the horizontal edges of each plate. No further partitioning is necessary since temperatures can be read directly from the heat transfer output. A line of code is appended importing the nodal temperatures from the previous heat transfer analysis. The program appends additional code to the basic model requesting a restart as well as defining the time step for the current iteration. For the initial iteration of the coupling procedure, code is appended applying an imperfection to the structural system as discussed in Section 3.4. As with the previous geometry update program, if plate failure has occurred, code is appended to deactivate the plate using an Abaqus model change interaction.

Finally the Python script 'plateFailureCheck' checks plate failure. After every iteration, the program checks plate failure based on a user-defined stress failure criterion. Panel failure and failure time points are written to a log file that is used to update the model geometries in the previously discussed 'upGeom' programs. The script checks if the von Mises stress exceeds a user defined stress criterion in a user-defined number of section points, and if so, the finite element is considered to have failed. Subsequently, a plate fails if a user-defined number of failed finite elements is found. Threshold values for the stress (typically the yield stress), the number of failed section points to consider the finite element to have failed, and the number of failed elements to be considered for the plate to have failed are requested from the user.

\section{Results}

The program FDS-2-Abaqus was used to study the failure progression of a thin-walled steel façade comprising 12 plates. Multiple simulations were performed using both one-way and two-way coupled CFD-FEM analyses, and both coarse and fine CFD meshes. The plates were assumed as structurally and thermally independent (untied) for the FE heat transfer and structural response analyses. However, the buckling analysis used for the initial imperfection input in the structural response model was modelled with tied panels, since an untied system would result in many buckling modes with identical eigenvalues and therefore inconsistencies in the initial imperfection. The one-way coupled (OWC) simulation consisted of a single iteration with a duration of $1800 \mathrm{~s}$. By using some preliminary experiments, the two-way coupled (TWC) simulation was subdivided into 12 iterations of $150 \mathrm{~s}$, where the model geometry was updated automatically after each iteration. Validation of the iteration time size is given in the next section. Finite element failure was assumed if the von Mises stress exceeded the yield stress in three of the exterior integration points. Plate failure was assumed when 13 finite elements had failed. The results for the failure progression of the one- and two-way coupled procedures, discretized using a coarse CFD mesh of cuboid cells with $0.30 \mathrm{~m}$ ribs, are shown in Figure 6. 

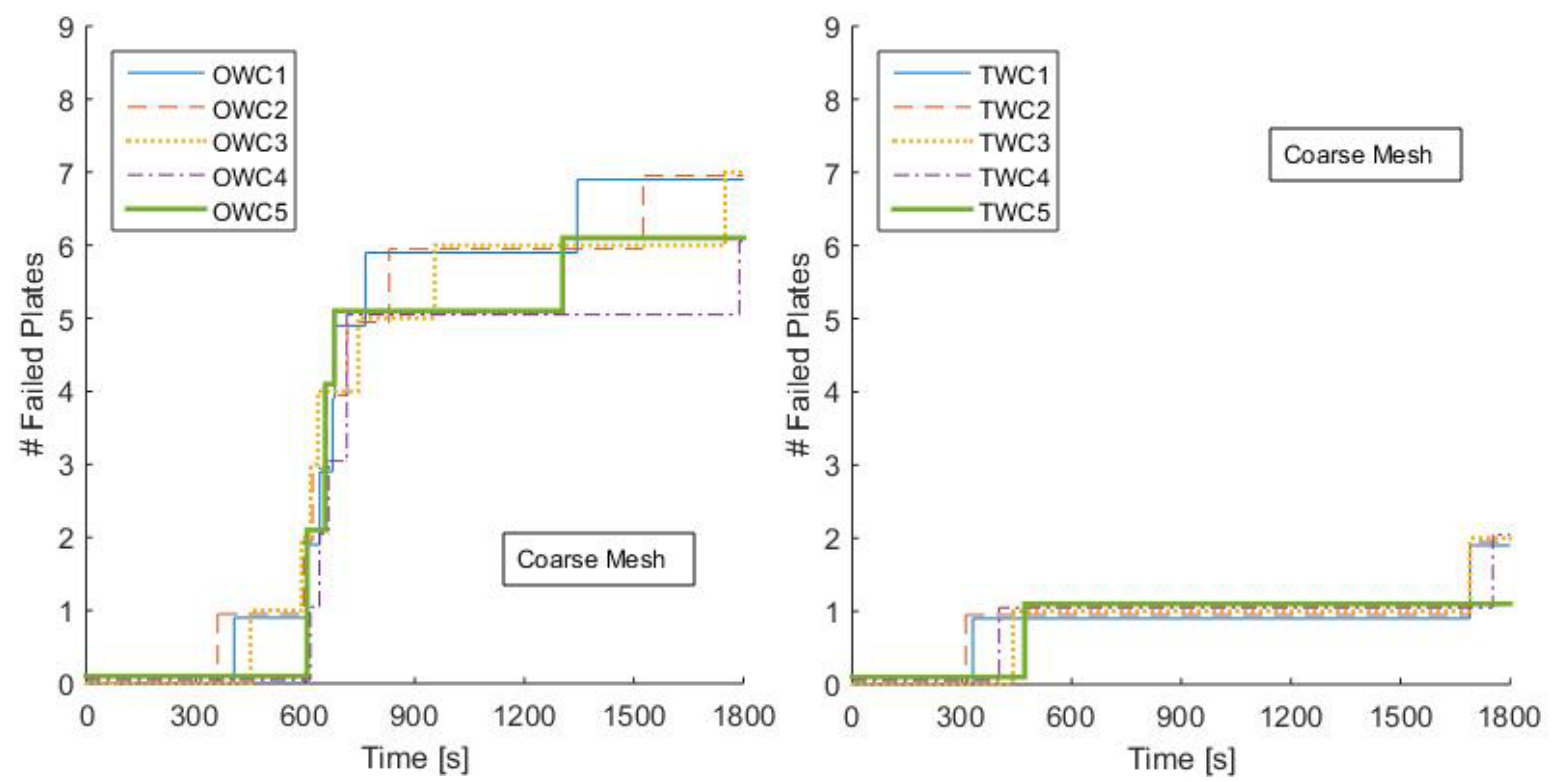

Figure 6. Failure progression for one-way (left) and two-way (right) coupling approaches using a coarse CFD mesh of cuboid cells with $0.30 \mathrm{~m}$ ribs

The results for the fine mesh of cuboid cells with $0.15 \mathrm{~m}$ ribs are shown in Figure 7. Typical Smokeview visualizations using one-way and two-way coupled analyses for the fine mesh are shown in Figure 8 after $700 \mathrm{~s}$ into the simulation.
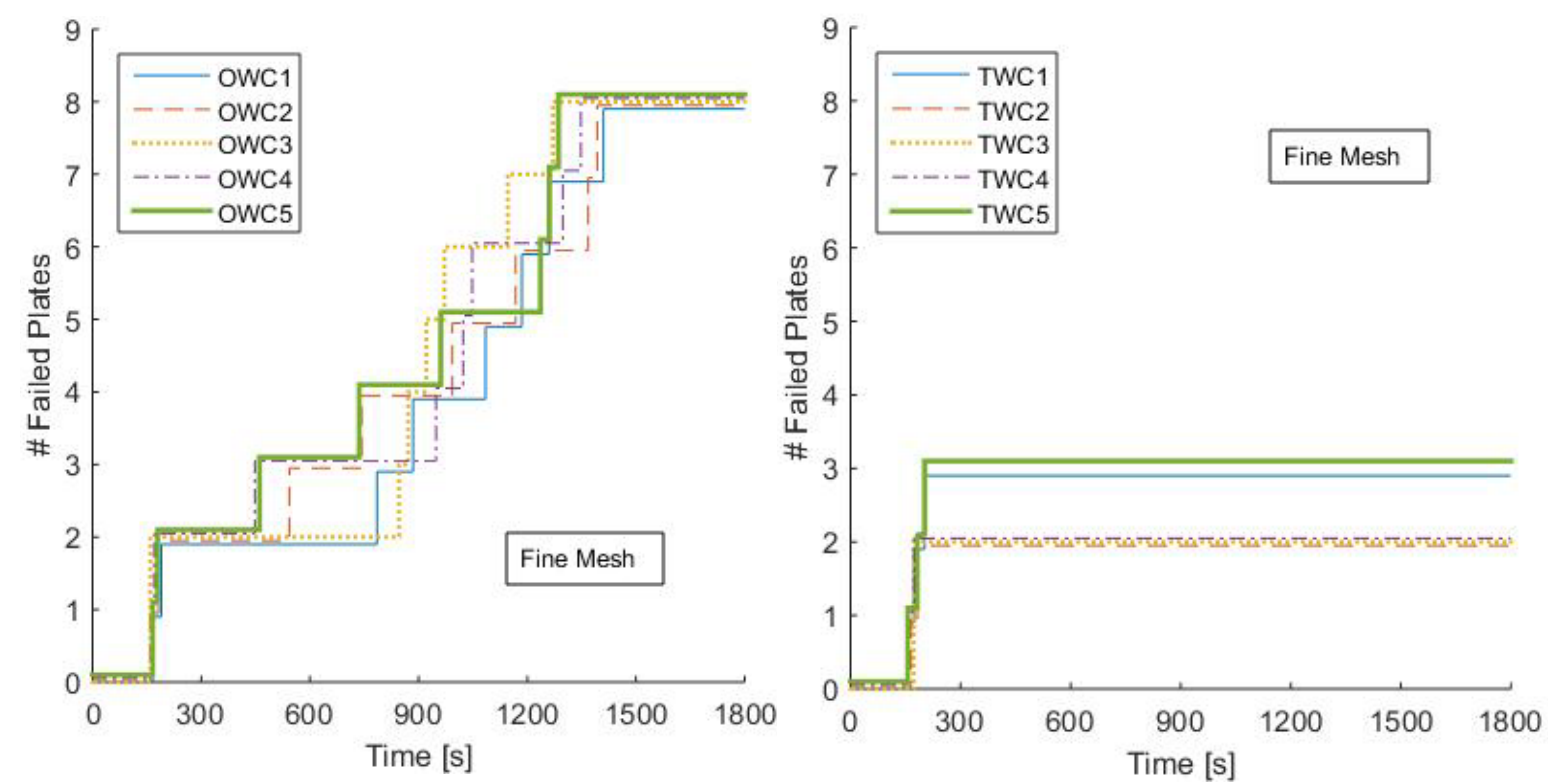

Figure 7. Failure progression for one-way (left) and two-way (right) coupling approaches using a fine CFD mesh of cuboid cells with $0.15 \mathrm{~m}$ ribs

The results in Figure 6 for the coarse mesh show a significant difference in failure progression between one-way and two-way coupled approaches. For the OWC, a total of 6 to 7 plates failed throughout the simulation, whereas for the TWC only 2 plates failed. Failure of the first plate should occur around the same time given that OWC and TWC approaches are identical until failure, and the subsequent removal of the first plate. This can indeed be seen in the figure, where failure of the first plate occurred concurrently at about the $400 \mathrm{~s}$ mark. The first plate to fail is plate number 4 . Similar results were obtained using the finer $0.15 \mathrm{~m}$ mesh as shown in Figure 7. For OWC using a fine mesh, a total number of 8 plates failed while 2 to 3 plates failed for TWC. As with the coarse mesh, initial failure occurred concurrently, although earlier (about the $160 \mathrm{~s}$ mark), and the first plates that failed were plates 4 and 7. 

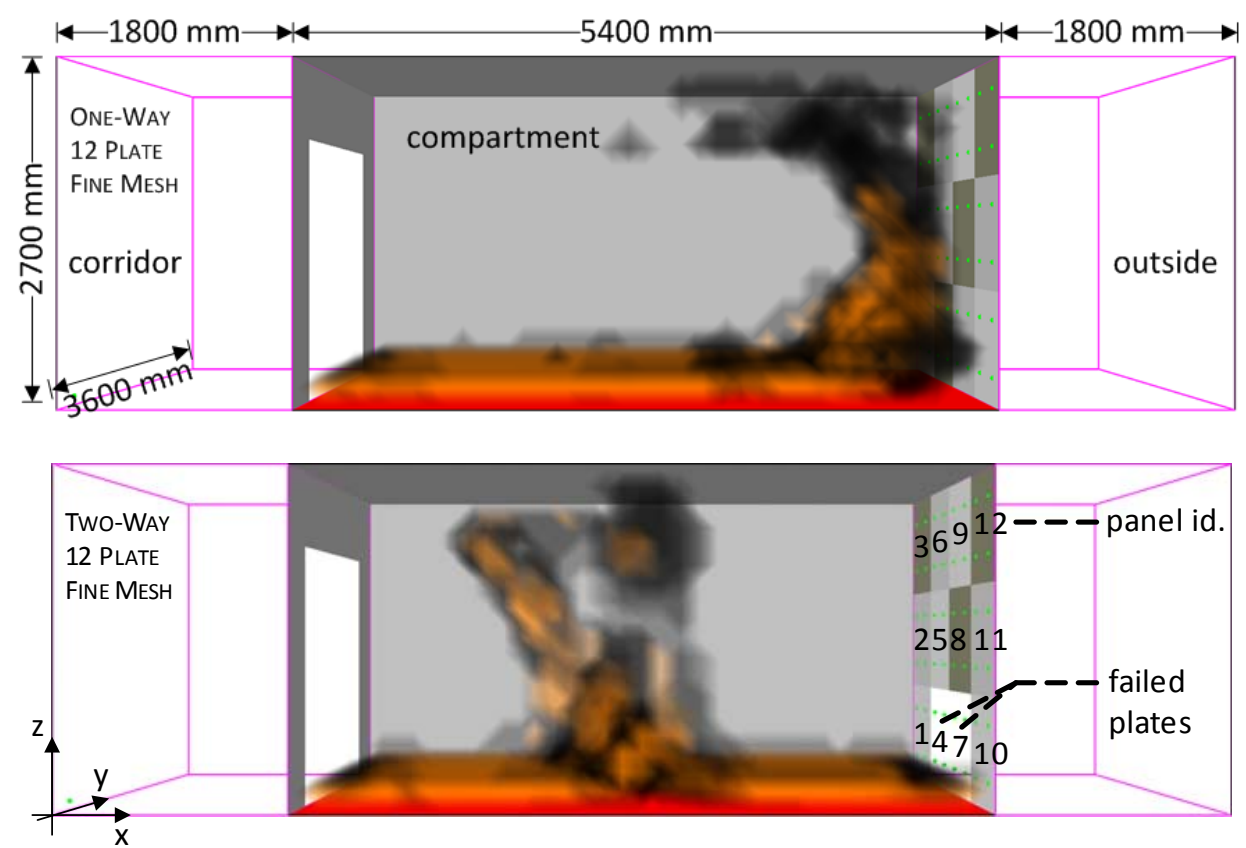

Figure 8. Smokeview visualizations at $700 \mathrm{~s}$ for one-way (top) and two-way (bottom) coupled simulations (fine mesh). (In the two-way coupled analysis, fire is redistributed to a more centralized position due to the additional airflow as a result of the geometric updates)

Although the various simulations differ slightly in failure progression, their overall behaviour is similar. The variations are governed by differences in the AST output from FDS, for simulations with exactly the same specifications (e.g. OWC1 to OWC5). In turn, this variation is believed to be caused by some form of randomness in the FDS simulations. Comparison of OWC approach with coarse and fine mesh shows a more regular (in time) failure progression for the TWC approach. For the TWC approach, 2 to 3 plates fail simultaneously for the fine mesh compared to failure of a single plate for the coarse mesh. The differences in failure progression, expressed in the number of failed plates, are best explained with the Smokeview visualizations in Figure 8. Initially the fire is concentrated on the right side of the compartment. Removal of the failed plates in the two-way coupled (TWC) analysis redistributes the fire to a more centralized position in the compartment, away from the structural façade. This limits both the thermal exposure to the façade and further failure of the façade. This redistribution of the fire is governed by the airflow drawn from outside. This is in contrast to one-way coupled (OWC) analysis, where the geometry is not updated throughout the simulation. For the OWC approach the simulated fire is concentrated on the right side of the compartment for the full duration of the fire resulting in an increased number of failed plates as a result of persistent thermal exposure.

\section{Verification}

Although many fire experiments have been carried out, to the authors' knowledge, no experimental results have been presented in the literature that explicitly show the mutual influence of fire and progressive structural behaviour (at the overall structural level). Hence at present, verification can only be undertaken based on fire simulations, thermomechanical model, and parts of the interaction.

For the fire simulations, two important verifications have been carried out. First of all the CFD mesh sizes have been varied, as presented in the previous section. Secondly, the room and fire scenario in the FDS model has been compared with an Ozone one-zone model. Figure 9 shows the temperature versus time for the Ozone model and the FDS model using 20 points equally spread throughout the room. As clearly shown in figure 9 both models exhibit qualitatively similar behaviour, and this is in the context of this paper, showing the effects of two-way coupling on the structural scale, regarded as sufficient. 


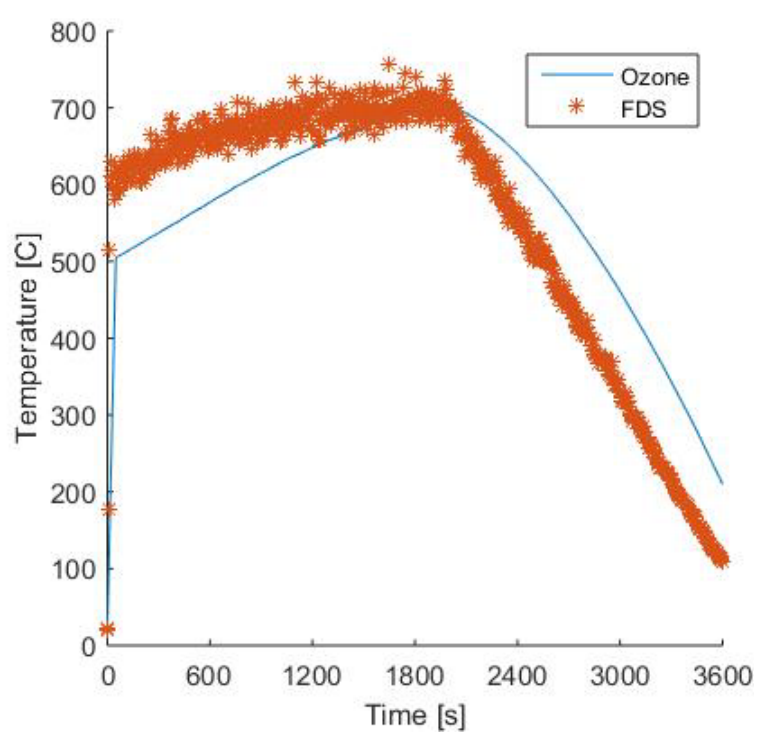

Figure 9. Temperature versus time plots from FDS and Ozone One-zone models

The thermomechanical aspects of the FE model have been verified as follows. As discussed in section 2.3 , the thermal stresses in a one-dimensional system should develop at a rate of $2.52 \mathrm{~N} /\left(\mathrm{mm}^{2 \circ} \mathrm{C}\right)$. For a single plate of $1.0 \mathrm{~m} \mathrm{x} 1.0 \mathrm{~m}$, heated from $0^{\circ} \mathrm{C}$ to $500^{\circ} \mathrm{C}$, this should induce a total stress equal to $1260 \mathrm{~N} / \mathrm{mm}^{2}$, that is, if the plate models a one dimensional situation and expansion in one direction is fully restricted-for free expansion the plate should expand $6 \mathrm{~mm}$. Figure 10 presents the results of such a plate from the FE model. For one plate (marked in the plot with +) the bottom and top edges are fixed in $y$-direction, whereas the left and right edges are free, which resembles a one-dimensional system. Indeed the thermal stress equals $1260 \mathrm{~N} / \mathrm{mm}^{2}$ due to fully restricted expansion in the $y$ direction, whereas the expansion in $x$-direction equals $6 \mathrm{~mm}$ (not visible). For another plate (marked with 0 ) all nodes of the bottom and top edges are fixed in $x$ and $y$-directions. The thermal stresses for this plate are higher, caused by expansion restriction in both for $x$ and $y$-directions. The maximum displacements of the left and right edges are now $-2.84 \mathrm{~mm}$ and $+2.84 \mathrm{~mm}$, respectively, so a smaller total expansion as the first plate (see also figure 10 on the left).
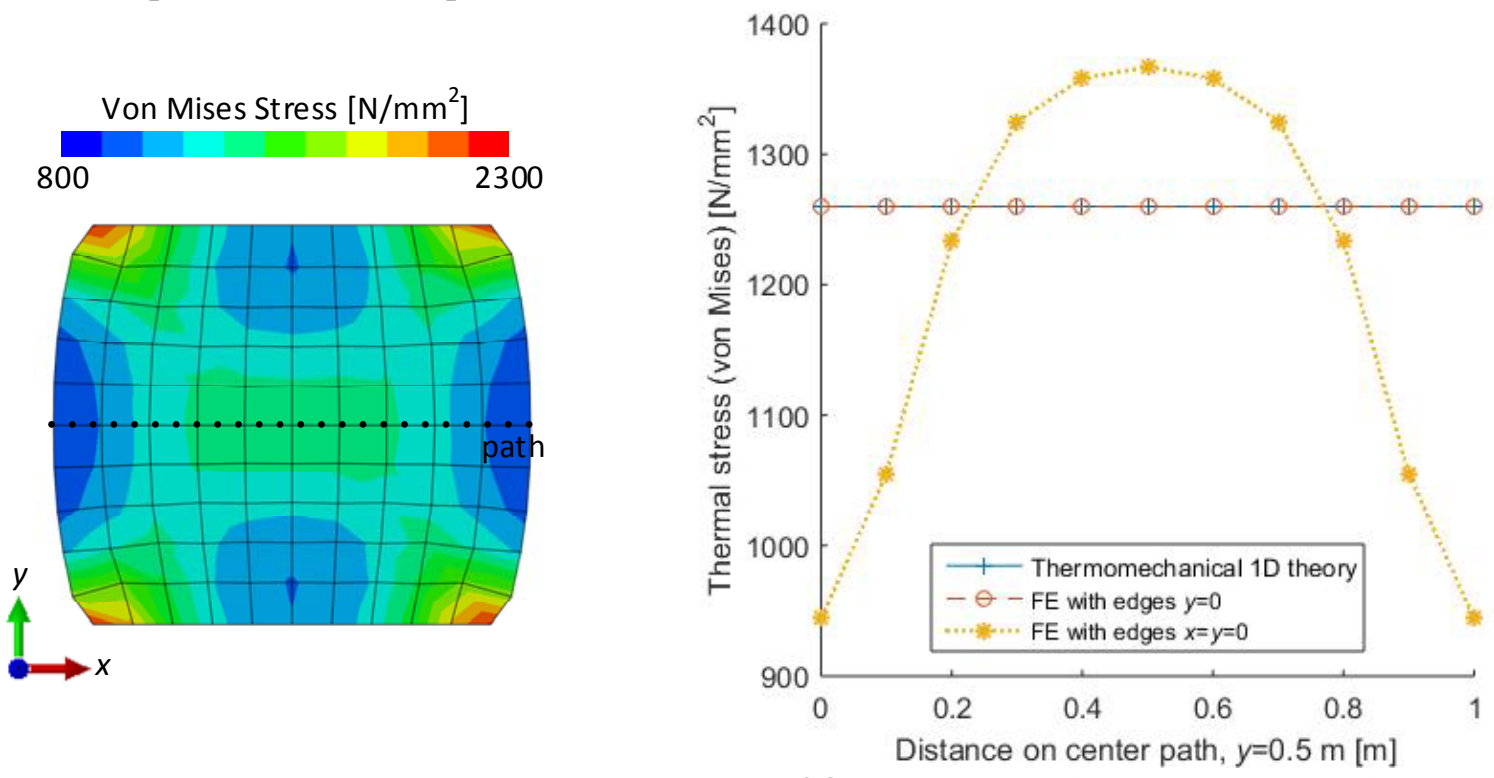

Figure 10. Stress due to temperature increase of $500^{\circ} \mathrm{C}$ for a plate with top and bottom edges restrained in $y$-direction (0) and both in $x$ - and y-directions $\left({ }^{*}\right)$. On the left von Mises stresses for $\left({ }^{*}\right)$ 
Mechanically, the FE model has been verified by isolating a single panel $\left(A_{\text {panel }}=0.81 \mathrm{~m}^{2}\right.$ and thickness $t_{\text {panel }}=3 \mathrm{~mm}$ ) from the structural analysis and loading it with a uniform (wind) pressure of $1.0 \mathrm{kN} / \mathrm{m}^{2}$. In the direction perpendicular to the plate, a hinged boundary condition is applied along its upper edge and a roller boundary condition along its lower edge. Using engineering theory for moment and displacement of a simply supported beam, $M_{\text {mid }}=\frac{1}{8} q l^{2}, \sigma=\frac{M z}{I}$ and $u_{\text {mid }}=\frac{5}{384} \frac{q l^{4}}{E I}$, gives a maximum bending stress of $67.5 \mathrm{~N} / \mathrm{mm}^{2}$ (see Figure 11) and an out-of-plane displacement of $18.1 \mathrm{~mm}$ in the middle of the plate. The isolated single panel in the FE model has the left and right edges constrained in $x$ - and $y$-directions and therefore only a simulation with Poisson's ratio equal to zero $(*$ in the plot of figure 11$)$ shows the bending stress correctly. Note that the small difference (note the selected $y$-axis range) is due to discretization; modelling the panel using $20 \times 20$ elements would result in a stress of $67.58 \mathrm{~N} / \mathrm{mm}^{2}$. Also the displacement is described correctly by the FE model to be $18.1 \mathrm{~mm}$. If Poisson's ratio is set to 0.29 , the constrained left and right edges influence the results, as shown in Figure 11 for a panel with 36 elements. In the plot, stresses are higher near the edges, consequently the stiffness is higher, as shown by the maximum displacement of $16.6 \mathrm{~mm}$.
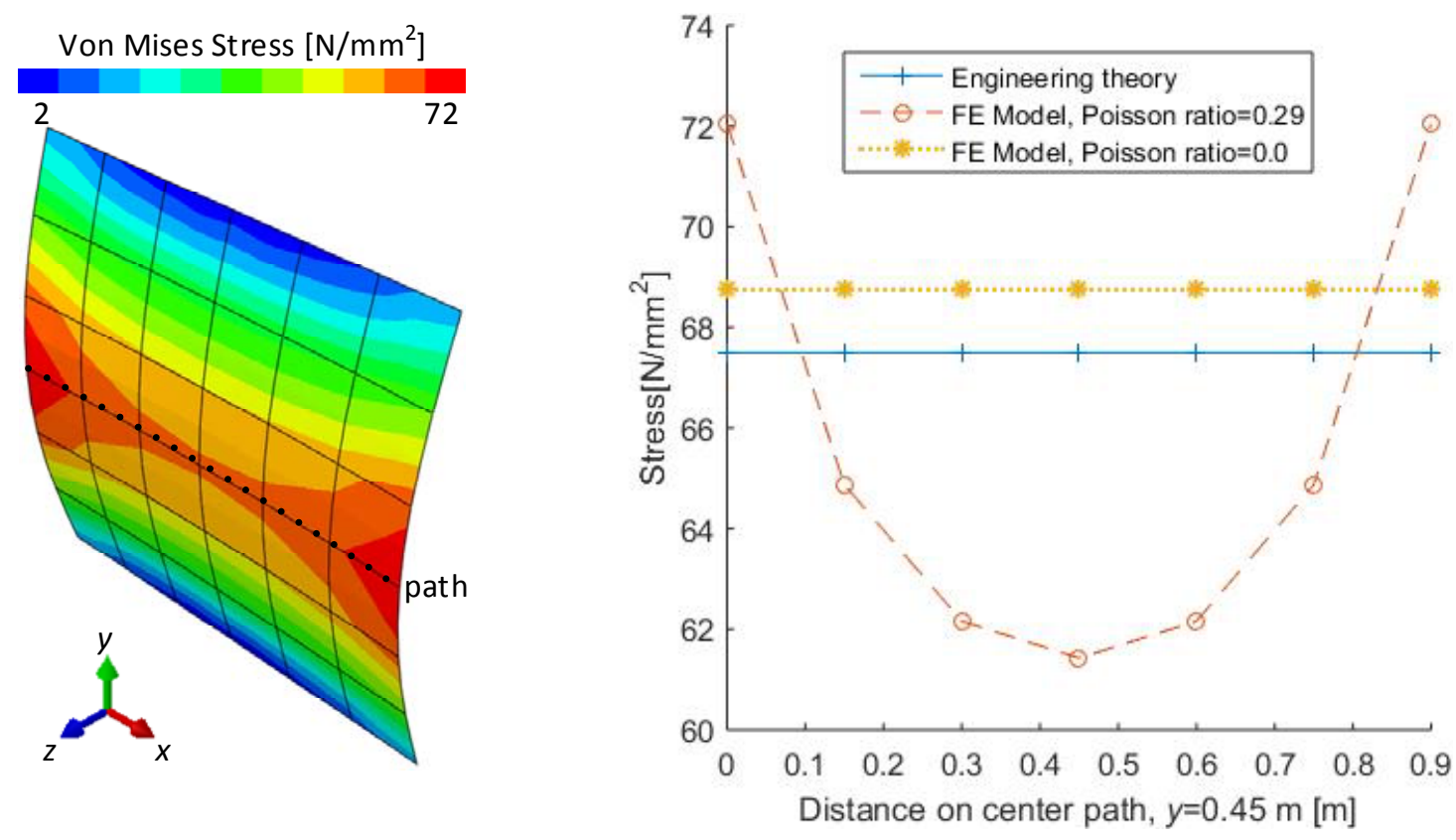

Figure 11. von Mises stress distribution for single panel loaded with a uniformly distributed (wind) pressure of $1.0 \mathrm{kN} / \mathrm{m}^{2}$

Besides the use of different mesh sizes as presented in the previous section, the two-way coupled analysis was additionally verified by running it for 600 seconds using iteration time steps of 30 (twice, marked A and B respectively), 60, 100, and 300 seconds using the coarse mesh, figure 12. Failure of plate 4 was recorded between 300 and 450 seconds for all but simulation 30(A). This agrees with the results recorded for the 150s iteration size presented previously. The delay of failure of plate number 4 for simulation 30(A) is similar to the delayed failure of the first plate in OWC5 as well as the delay of the second plate in TWC5 (see figure 6).

To study the sensitivity of the problem for other boundary conditions, another coupled simulation was set up with identical input variables and using the coarse mesh. However, compared to the previous simulations, the bottom row of panels was excluded from failure, e.g. being a thick concrete wall below a window. This eight-plate simulation resulted in an initial failure of the corner plates ( 3 and 12 in Figure 8) around 680 to $800 \mathrm{~s}$ for both OWC and TWC analyses. For OWC analysis, additional failure occurred in the panels directly below the corner panels (2 and 11 in figure 8) at about 910 to 1020 s. A Smokeview visualization for a TWC eight-plate simulation is shown in figure 13. In contrast to the 12-plate simulations, the fire stays concentrated at the right side of the compartment. However, 
unlike in OWC simulations, no subsequent plate failures occurred for TWC simulations, possibly due to the release of thermal energy to outside the compartment, thereby reducing the thermal load on neighbouring plates.

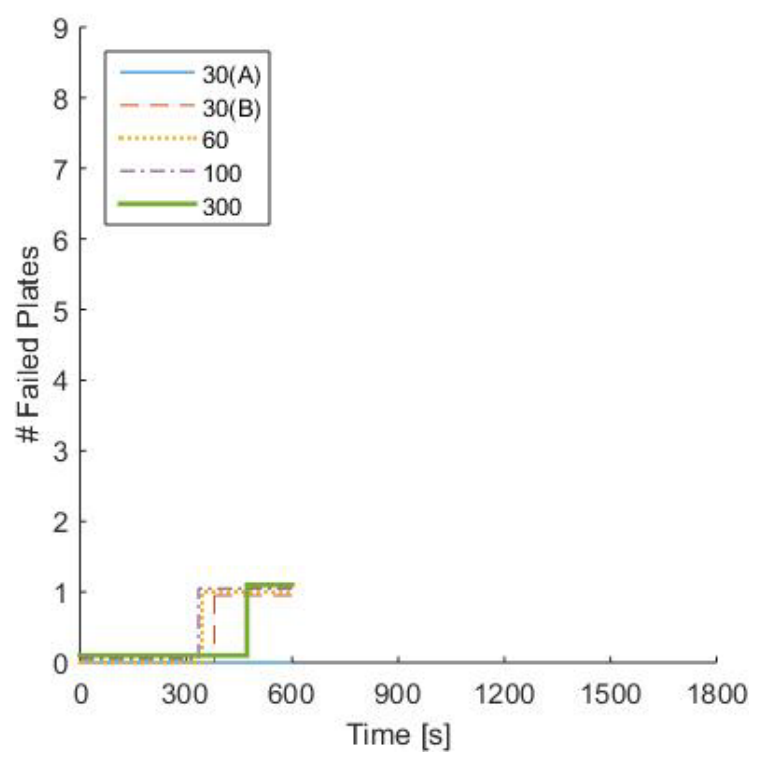

Figure 12. Failure time of first plate (plate 4) for varying iteration sizes using a coarse CFD mesh of cuboid cells with $0.30 \mathrm{~m}$ ribs

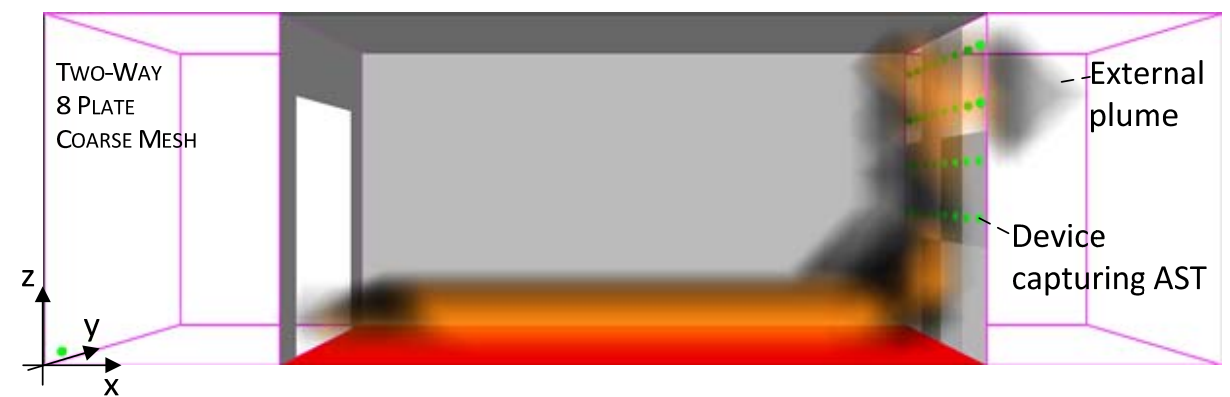

Figure 13. Smokeview visualization for the eight plate two-way coupled analysis at $865 \mathrm{~s}$

\section{Discussion}

The geometric updates in the two-way coupling analysis redistribute the fire and, evidently, change the thermal exposure of surrounding structural elements. But also, at least for the specific examples used, the middle section of the ceiling is exposed to an increased thermal load as a result of the geometric updates. This indicates that, although not taken into account in this initial study, this could result in completely different failure mechanisms for the structural system as a whole when taking into account geometric changes in a two-way coupled analysis.

Slight variation of the input variables influenced the failure times and progression order although the overall failure behaviour remained relatively the same. Pilot experiments showed that changing the structural initial imperfections, output request time interval, and two-way coupling iteration size, the latter as discussed in section 6 "Verification", all affected the failure progression. A detailed parametric study, preferably verified using real life fire tests, could help in both mapping and understanding these influences. In addition, variations could be a result of the sensitivity of the stress based failure criterion used in this study. Incorporating a more detailed and realistic failure criterion could therefore be helpful. 
The fire behaviour illustrated in Figures 8 and 13 may not accurately simulate a real life fire. The symmetric distribution of the fire in the centre, while the openings on either side differ greatly, points to a questionable difference in air velocities. In addition, a fuel controlled fire was assumed whereas compartment fires typically are ventilation controlled after flashover. Plate failure in a ventilationcontrolled fire would result in an additional oxygen source due to backdraft and thus in an overall increase in the heat release rate. This will increase the thermal load on exposed structural elements and possibly accelerating the failure progression of structural elements in two-way coupled simulation, compared to one-way coupled simulation.

The façade was modelled as a structurally and thermally independent system of 12 panels. In terms of the specific FE program Abaqus used in this study, the panels were "untied". Several attempts were made to use a tied multiple panel system, but they proved to be challenging. For the heat transfer analyses, the plates were tied using a master and slave surface definition. Deactivating a slave surface did not complicate the initial, nor any restart analyses. However, when a master surface was removed, the analysis aborted due to the occurrence of zero pivots (indicating rigid body movements). A possible solution can be found in modelling the façade as a single part containing multiple areas representing the plates that can be deactivated, effectively removing the ties and therefore the challenges associated with the ties. Although this would work for this specific approach, it would not function for more detailed models, for instance a façade wall assembled of several columns, struts, panels, and fasteners. Another possible solution is to "remove" the plate by decreasing its conductance. The main advantage of this approach is that no plate deactivations nor TIE constraint suppressions need to be introduced in the model. In the structural response analyses, the plates were tied using a master and slave edge definition. As for the heat transfer analyses, deactivating the plates associated with the slave edges did not influence the initial nor the restart analysis. However, deactivating the master and its associated TIEs caused the underlying boundary conditions to disappear, which led to rigid body rotations. In addition, removal of panels caused a sudden stress and stiffness change which proved challenging for the solver. A possible solution is to virtually remove the plate by lowering its stiffness, similar to the heat transfer analysis discussed above. More details can be found in [16].

Limitations of this research presented in this paper are due to the initial assumptions, the lack of experimental verification, and the specific application of FDS and Abaqus, although the overall approach should be applicable to other CFD and FE codes. Nevertheless, it is clear that the influence of structural updates, at the structural level, is of significant importance for future research, taking into account possible improvements of the models, scripts and simulations.

\section{Conclusions}

This paper has shown the feasibility of two-way coupled CFD fire simulations to FE heat transfer and structural response analyses, specifically at the structural level. It also presents adequate tools to facilitate this coupling, and illustrates the effectiveness of two-way coupling by comparing the failure progression of a 12-plate thin-walled steel façade in one-way and two-way coupled fire to thermomechanical analysis.

The application of the newly developed FDS-2-Abaqus program shows a significant difference in the failure progression of a façade in a one-way or a two-way coupled analysis. This difference was caused by the change in fire propagation due to geometric updates in the fire, heat transfer and structural response models. However, it is too early to give an all-conclusive answer on the effectiveness, mainly due to the lack of experimental verification and the approach used.

Although limited in its current state, this study using FDS-2-Abaqus program has established a preliminary framework for the use of two-way coupling in the field of structural fire safety engineering. More specifically, it can contribute to an improved understanding of both the structural response to fire and the response of fire propagation to structural changes. It allows extensive parametric studies on specific scenarios which would be virtually impossible, or economically impracticable using real life fire tests. 
Future research could focus on the implementation of a more realistic ventilation controlled fire, typical for compartment fires, by including a fully modelled interior. Failure of a façade panel in a ventilation controlled fire could cause backdraft and therefore result in a significant change in oxygen supply and subsequently the failure progression in a two-way coupled analysis. Another recommendation is to develop a model for a detailed (tied) structural system comprising a full façade system using columns, struts, panels and possibly fasteners. This can include a further development of the tyings used in these assembled models, possibly by using the approach of virtual removal by reducing conductivity or stiffness.

If the above mentioned improvements are implemented, the proposed method in this paper can be used in practical performance based fire safety designs. A thorough verification study is required using a variety of realistic full-scale experiments, which investigate explicitly the mutual influence of fire and progressive structural behaviour at the overall structural level.

\section{References}

[1] European Committee for Standardization, EN 1991-1-2, Eurocode 1: Actions on structures - Part 1-2: General actions - Actions on structures exposed to fire, Brussels, Belgium: European Committee for Standardization, 2012.

[2] D. Duthinh, K. McGrattan, A. Khaskia, Recent advances in fire-structure analysis, Fire Safety Journal 43 (2008) 161-167.

[3] National Institute of Standards and Technology (NIST),, Federal Building and Fire Safety Investigation of the World Trade Center Disaster: Final Report of the National Construction Safety Team on the Collapses of the World Trade Center Towers (NIST NCSTAR 1), Gaithersburg, MD, USA, 2005.

[4] X. Yu, A.E. Jeffers, A comparison of subcycling algorithms for bridging disparities in temporal scale between the fire and solid domains, Fire Safety Journal 59 (2013) 55-61.

[5] P.A. Beata, A.E. Jeffers, Spatial homogenization algorithm for bridging disparities in scale between the fire and solid domains, Fire Safety Journal 76 (2015) 19-30.

[6] K. Prasad, H.R. Baum, Coupled fire dynamics and thermal response of complex building structures, Proceedings of the Combustion Institute 30 (2005) 2255-2262.

[7] K. McGrattan, R. Mcdermott, C. Weinschenk, K. Overholt, S. Hostikka, J. Floyd, NIST Special Publication 1019, Sixth Edition, Fire Dynamics Simulator, User's Guide, Gaitersburg, USA: National Institute of Standards and Technology, U.S. Department of Commerce, 2013.

[8] H.R. Baum, Simulating fire effects on complex building structures, Mechanics Research Communications 38 (2011) 1-11.

[9] S. Welch, S. Miles, S. Kumar, T. Lemaire, A. Chan, FIRESTRUC - Integrating advanced three-dimensional modelling methodologies for predicting thermo-mechanical behaviour of steel and composite structures subjected to natural fires, Fire Safety Science 9 (2008) 1315-1326.

[10] C. Luo, L. Chen, J. Lua, P. Liu, Abaqus Fire Interface Simulator Toolkit (AFIST) for Coupled Fire and Structural Response Prediction, in: Proceedings AIAA/ASME/ASME/ASCE/AHS/ASC Structures, Structural Dynamics and Materials Conference, April 12-15, 2010, Orlando, Florida, USA, volume 4, 3361-3380.

[11] L. Chen, C. Luo, J. Lua, FDS and Abaqus Coupling Toolkit for Fire Simulation and Thermal and Mass Flow Prediction, Fire Safety Science 10 (2011) 1465-1477.

[12] U. Wickström, D. Duthinh, K. McGrattan, Adiabatic surface temperature for calculating heat transfer to fire 
exposed structures, In: Proceedings 11th International Interflam conference, September 3-5, 2007, London, England, Vol.2, 943-953.

[13] D. Banerjee, W. Hess, M. Olano, J. Terrill, Visualization of structural behavior under fire, National Institute of Standards and Technology, NISTIR7619, Gaitersburg, USA: National Institute of Standards and Technology, U.S. Department of Commerce, 2009.

[14] J. Silva, A. Landesmann, F. Ribiero, Fire-thermomechanical interface model for performance-based analysis of structures exposed to fire, Fire Safety Journal 83 (2016) 66-78.

[15] C. Zhang, J.G. Silva, C. Weinschenk, D. Kamikawa, Y. Hasemi, Simulation Methodology for Coupled FireStructure Analysis: Modeling Localized Fire Tests on a Steel Column, Fire Technology 52 (2017) 239-262.

[16] J.A. Feenstra, FDS-2-Abaqus: C++ Managed Automated Python Scripted CFD-FEM Coupling, Additionally assessing two-way coupling effectiveness, M.Sc.-thesis Eindhoven University of Technology, Department of the Built Environment, Unit Structural Design, The Netherlands. 